\title{
Scale dependent effects of native prey diversity, prey biomass and natural disturbance on the invasion success of an exotic predator
}

\author{
Lauren M. Pintor · Andrew Sih
}

Received: 27 June 2010/Accepted: 26 October 2010/Published online: 12 November 2010

(C) The Author(s) 2010. This article is published with open access at Springerlink.com

\begin{abstract}
There is growing support for the general notion that the drivers of invasion success often shift from biotic to abiotic factors with increasing spatial scale. Most of this research, however, has been conducted on a single trophic level; i.e. it has primarily looked at how the diversity of native competitors may influence invasion success. Less attention has been paid to understanding how native prey diversity may influence the invasion success of exotic predators and whether such biotic factors are scale-dependent. We used a hierarchical spatial survey of 17 stream communities to test whether native prey diversity, along with native prey biomass, algal resource abundance and annual stream discharge, influenced the abundance of an exotic crayfish predator, and whether the importance of these factors were scale-dependent. We used a hierarchical generalized linear model to evaluate the influence of these community and stream characteristics on exotic crayfish abundance at both the transect scale $\left(1 \mathrm{~m}^{2}\right)$
\end{abstract}

L. M. Pintor $(\bowtie) \cdot$ A. Sih

Department of Environmental Science and Policy, University of California-Davis, One Shields Avenue, Davis, CA 95616, USA

e-mail: laurenpintor@gmail.com

Present Address:

L. M. Pintor

Odum School of Ecology, University of Georgia,

140 E. Green Street, Athens, GA 30602, USA and the stream scale $\left(400 \mathrm{~m}^{2}\right)$. Our results indicated that at the stream scale, high stream discharge significantly limited invader abundance. However, at the smaller transect scale, native prey biomass was a significant driver of invasion success and positively correlated with invader abundance. We suggest that our results add to the emerging pattern that abiotic processes are stronger determinants of invasion success at large spatial scales, whereas biotic processes become more important with decreasing spatial scale. However, for predator invasions, prey biomass, not prey diversity may be a more important for driver of invasion success at small spatial scales.

Keywords Biological invasions - Prey diversity . Predator invasions $\cdot$ Scale-dependent $\cdot$ Natural disturbance

\section{Introduction}

Studies of biological invasions aim to understand the factors that influence the vulnerability of native communities to invasion by exotic species. Much attention has been given to the influence of native species diversity on the invasion success by exotic species (Stohlgren et al. 2006a; Levine and D'Antonio 1999; Byers and Noonburg 2003; Fridley et al. 2007). This research has provided great insights into the scale dependent relationship between native species richness and community invasibility 
(Fridley et al. 2007). Specifically, at small spatial scales, biotic interactions tend to have a strong influence over the invasion success of exotic species whereby high native species richness tends to provide resistance to invasion (Levine et al. 2004; Levine and D'Antonio 1999). But at broader spatial scales, studies have found that abiotic factors such as disturbance rates and environmental heterogeneity more strongly influence the relationship between native species richness and invasion success (Stohlgren et al. 2006a, b). Thus, the general notion to date is that drivers of invasion success shift from biotic to abiotic factors with increases in spatial scale (Fridley et al. 2007). However, this has primarily been observed within a single trophic level (i.e. invasion as a function of the diversity of native competitors). Far less empirical attention has been paid to understanding how native prey diversity may influence the invasion success of predators (Donlan and Wilcox 2008), and whether such biotic factors are scale-dependent, despite the well known impacts that exotic predators have been shown to have on prey (Cox and Lima 2006).

In general, from the prey's perspective, prey diversity is expected to decrease the impacts of predators on prey biomass (Duffy 2002; Hillebrand and Cardinale 2004). For example, by chance alone, high prey diversity may increase the number of nonedible or unpalatable prey species in a community (Duffy 2002; Leibold 1989). If resistant prey can compensate for prey subject to predation, then overall prey biomass may go unchanged in the face of predator introductions. However, from an invading predator's perspective, higher prey diversity may mean more edible or naive prey species, and thus a greater probability of a successful invasion and potential for large impacts (Sih et al. 2010).

Prey diversity alone, however, is unlikely to explain the invasion success of exotic predators. Multiple factors, including resource abundance and abiotic factors, have been suggested to covary with native species richness to explain invasion success of exotic species (Rejmanek 2003; Taylor and Irwin 2004; Marchetti et al. 2004b). Clearly, the abundance or biomass of edible prey should influence the invasion success of predators. Additionally, abiotic forces, such as natural disturbances, may also control predator invasions. For example, annual flood events and natural variability in stream flow often ameliorate the impacts of exotic predatory fish and crayfish on prey by reducing predator abundances (Moyle and Light 1996a; Gamradt and Kats 2002; Poff and Ward 1989). However, similar to the patterns found with native species diversity at a single-trophic level, the drivers of predator invasions may also be scaledependent. Abiotic forces (e.g. flow variability) might drive predator invasions at larger-spatial scales, but biotic forces (e.g. prey diversity and biomass) might be more important at smaller scales.

Here we evaluated the scale-dependent relationships between prey diversity, prey biomass and annual variability in natural stream discharge on the invasion success of an introduced predator, freshwater crayfish. In general, exotic freshwater crayfish are highly successful invaders (Lodge et al. 2000) that have been frequently shown to have large impacts on native benthic invertebrate prey (Mccarthy et al. 2006; Lodge et al. 1994; Wilson et al. 2004). Exotic crayfish impacts often arise through their ability to reach high abundances, however, many populations often remain at low densities (Nyström 2002). High annual variability in stream discharge has been shown to limit crayfish density, as well the outcome of competitive interactions (Gamradt and Kats 2002; Light 2003; Kerby et al. 2005). However, few studies have evaluated how prey diversity, prey biomass and stream discharge simultaneously, affect the invasion success of exotic crayfish predators and whether these drivers are scale dependent.

Specifically, we distinguished how these three factors simultaneously affect the abundance of the exotic signal crayfish (Pacifastacus leniusculus Dana). Signal crayfish have been widely introduced throughout Europe and parts of North America and have had broad negative impacts as predators on aquatic food webs and in particular, on native crayfishes (Lodge et al. 2000; Taylor 2002; Light et al. 1995; Nystrom 2005). Native from far northern California to British Columbia, signal crayfish have been introduced throughout California primarily via bait-bucket introductions (Riegel 1959). Its introduction into the Pit River drainage in northern California (Shasta County) has caused the decline of the endangered Shasta crayfish (Pacifastacus fortis) (Light et al. 1995; Ellis 1999).

In this study, we used a hierarchical study design to survey 17 streams across two watersheds to evaluate the scale-dependent relationship between prey diversity, prey biomass and hydrologic 
variability and the abundance of exotic signal crayfish. Additionally, because crayfish are known omnivores and often consume both animal and plant material (Nyström 2002), we also included algal biomass as another factor that may influence the abundance of exotic signal crayfish. This hierarchical design was used to capture the influence of these factors across two spatial scales; small, "transect" scale $\left(1 \mathrm{~m}^{2}\right)$ and larger, "stream" scale $\left(400 \mathrm{~m}^{2}\right)$. In recognition of the fact that different processes are likely to influence species at multiple spatial scales, hierarchical regression models have begun to be more widely used by ecologists to understand complex relationships at different scales (Diez et al. 2009; Diez and Rulliam 2007; McMahon and Diez 2007).

\section{Study area}

The study was conducted across 17,1 st-3rd order streams within the lower Pit River drainage (Shasta County; 9 streams) and the upper Sacramento River drainage (Siskiyou County; 8 streams) in northern California (Fig. 1a). All streams in the upper Sacramento River drainage are run-off fed streams. Five of the nine streams sampled in the lower Pit River were spring-fed streams. Stream altitudes varied from 500 to 1,400 , but most were about $900 \mathrm{~m}$ elevation. Thirteen streams were sampled between July and August of 2003, and four streams were sampled in July 2004. There were no systematic differences between years with respect to the type (i.e. run-off and spring-fed) of stream surveyed, or the river drainage. Additionally, it is estimated that the large majority of these streams were all invaded between 1980 and 1986 (Light et al. 1995).

\section{Methods}

Within each stream, a $90 \mathrm{~m}$ stretch was divided into six equally spaced transects (Fig. 1b). Each transect was divided into 3 equally spaced $1 \mathrm{~m}^{2}$ sub-sections. Transects were sampled starting downstream and working upstream. In each sub-section a standard, representative stone $\left(\sim 15 \mathrm{~cm}^{2}\right)$ was collected to measure algal biomass. Algae and organic material was scraped from the surface of each stone with a stiff brush and rinsed with $250 \mathrm{ml}$ of stream water into a pan, transferred into a dark bottle and frozen. In the laboratory, a $60 \mathrm{ml}$ subsample was filtered through a pre-ashed $45 \mu \mathrm{m}$ glass-fiber filter, dried to a constant mass at $100^{\circ} \mathrm{C}$ for $24-\mathrm{h}$, weighed and ashed at $500^{\circ} \mathrm{C}$ for $1 \mathrm{~h}$, and reweighed to yield ashfree dry mass (AFDM).

Within each transect, two $30.5 \mathrm{~cm} \times 30.5 \mathrm{~cm}$ samples of the benthos were taken from the center and left or right sub-section, alternating left or right side with each transect. Samples were taken with a Dframe net $(\mathrm{mesh}=250 \mu \mathrm{m})$ and preserved in $90 \%$ ethanol and returned to the laboratory for identification of macroinvertebrates to family. Samples that had a wet weight of more than $30 \mathrm{~g}$ were subsampled to one-quarter the total weight. Macroinvertebrate diversity was calculated at each sub-section using the Shannon-Weaver Index. The average mass of individuals from each taxon was calculated by weighing ten individuals from each taxon after they were dried
Fig. 1 a Map of study area showing the 17 sites sampled. The inset gives the location of the study area within California. Stars indicate streams sampled with the lower Pit River and upper Sacramento River watersheds. b Diagram of within-stream sampling scheme a

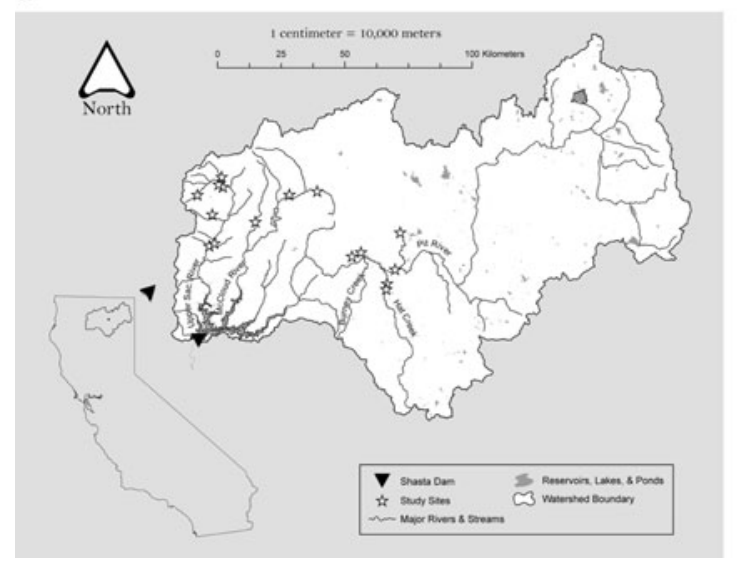

b

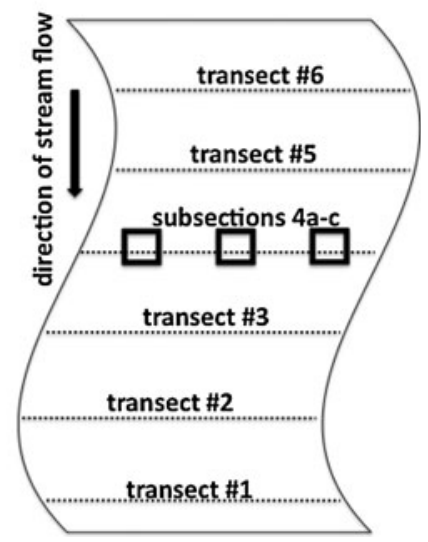


at $100^{\circ} \mathrm{C}$ for $1 \mathrm{~h}$. The mean mass of each taxon was then multiplied by the number of individuals per sample to get the total macroinvertebrate biomass.

Visual estimates of snails and crayfish were made by snorkeling at each sub-section within transects. Because snails are known as a strongly preferred prey item of crayfish (Nyström and Perez 1998; Alexander and Covich 1991), snails were identified to species and counted on a $30.5 \times 30.5 \mathrm{~cm}$ area. Crayfish were found by turning over cobbles and boulders within a $1 \mathrm{~m}^{2}$ area. Crayfish were captured by hand and the following information collected: (1) species, (2) total carapace length $(\mathrm{mm})$, (3) chelae length $(\mathrm{mm})$ and (4) sex. Young of year crayfish $(<15 \mathrm{~mm}$ carapace length) were not captured by hand, but rather just visually counted.

Within each transect, we measured and recorded the width of each transect and the depth and current velocity (using a Marsh-McBirney Flo-mate Model 2000) at each sub-section. We used this data to calculate stream discharge at each transect. We used geographical information system software (ArcGIS Ver. 9.2, ESRI 2006) to characterize stream-level site environmental variables that are known correlates of discharge. For each site, we calculated the elevation and drainage area from United States Geological Survey $10 \mathrm{~m}$ digital elevation models, and we calculated the annual precipitation and percent precipitation in the month of January using PRISM climatic data representing mean monthly estimations for 1971-2000 (Daly et al. 1994; Doggett et al. 2004). Percent precipitation was used for January to characterize annual winter flood events that naturally occur each year in both watersheds. We used the 30 water-year time series to reflect periods of prolonged drought (1976-1977, 1987-1988+), the wettest year on record (1983) and the flood year of record (1997) (i.e. a variety of hydrological conditions). These values were area weighted and temporally averaged, and while not indicative of actual streamflow for the year in question, should be highly representative of their relative differences.

\section{Model variables}

Variable used in analyses included transect stream discharge, elevation, drainage area, annual precipitation, January precipitation, algal biomass measured as ash free dry mass (AFDM), diversity and biomass of macroinvertebrates, biomass and density of snails, and density of crayfish. Data from each sub-section were pooled to derive a transect average for each variable. Transects were then pooled to come up with a stream average for each variable (except for discharge which was estimated using GIS data). One-way ANOVAs using stream as the factor were run on each variable and the residuals were analyzed using a Shapiro-Wilk test to test for normality. Residuals were normally distributed for all variables. Finally, the averages of all variables at both the stream and transect scale that were not normally distributed were $\log$ transformed. All analyses were performed in $\mathrm{R}$ version 2.8.1.

All variables used were examined for colinearity. When two or more variables were significantly correlated (Bonferroni $P<0.05$ ), Principle Component Analysis (PCA) was used to reduce the variables into a single measure. Across streams and at the transect scale, macroinvertebrate biomass, snail biomass and density were all highly correlated and reduced into a single "prey biomass" variable using a PCA $(72.29 \%$ of the variance explained by the first loading score). Elevation, drainage area, annual precipitation and percent precipitation for January were all highly correlated and were reduced into a single "discharge" variable. The first loading score explained $45.47 \%$ of the variation.

\section{Statistical analysis: hierarchical linear model}

In order to simultaneously consider the influence of prey diversity, biomass, algal biomass and stream discharge on exotic crayfish abundance at multiple spatial scales, a hierarchical generalized linear model was implemented. Hierarchical models use parameters that can vary at more than one level and have been frequently been advocated and used to look at the relationship between different spatially nested data and species distributions and abundance (Diez and Pulliam 2007; Latimer et al. 2006; McMahon and Diez 2007). We used this approach to incorporate the spatial structure (i.e. smaller, transect scale $\left(1 \mathrm{~m}^{2}\right)$ and larger, stream scale $\left(400 \mathrm{~m}^{2}\right)$ of the variables in the model.

There were four independent variables each at the transect and stream scale that were used in the model. Independent variables at the transect level included discharge, prey diversity, prey biomass and algal biomass. The same independent variables were used 
at the stream scale. The dependent variable in the model was crayfish density. Analyses were conducted in $\mathrm{R}$ statistical computing 2.8.1 using lmer in the lme4 package.

We first fitted an unconditional model (without independent variables) to determine whether there was variation in crayfish density between streams. The unconditional model for crayfish density (dependent variable), for transect $i$, in stream $j$, is:

$C R A Y_{i j}=\gamma_{00}+\mu_{0 j}+r_{i j}$

where $\gamma_{00}$ is the stream-level intercept, $\mu_{0 j}$ is the effect of stream $j$ on crayfish density holding all stream-level predictors constant and $r_{i j}$ describes the random error on crayfish density which is assumed to be normally distributed with mean zero and variance $\sigma_{i j}^{2}$. Therefore, streams in this study correspond to the group level predictor and transects to individual-level predictor of typical hierarchical linear models (McMahon and Diez 2007). The variance component of every transect has two parts, individual variance (taking into account groupvariance) and group variance (taking into account individual-variance).

With the unconditional model we calculated the intraclass correlation coefficient (ICC) to quantify the variation between streams where ICC is equal to:

$\mathrm{ICC}_{\text {stream }}=\sigma_{\text {stream }}^{2} /\left(\sigma_{\text {residual }}^{2}+\sigma_{\text {stream }}^{2}\right)$

The ICC is used for linear models and is constrained between 0 and 1 . Values near 0 represent no variation at the stream level and values closer to 1 suggest that variation between streams is important to understanding transect-level differences (Merlo et al. 2005).

We then created a partial model (i.e. random effects model) by adding transect level predictor variables (i.e. did not include each of the stream-scale predictor variables) in order to determine how much stream-level variation remains after accounting for transect-level variables. For example, if we were to only add prey biomass at the transect level then:

$$
C R A Y_{i j}=\gamma_{00}+\mu_{1 j} \text { preybio }_{i j}+\mu_{0 j}+r_{i j}
$$

where $\mu_{1 j}$ preybio $_{i j}$ represents prey biomass at the transect-level. We calculated the ICC score to quantify the amount of variation explained by adding in the transect-level predictor variables.
Last, we created the full model by adding the stream-scale predictor variables, along with the transect-scale predictor variables. For example, a model containing only the transect-level predictor preybiomass and the steam-level predictor discharge would be written as:

$C R A Y_{i j}=\gamma_{00}+\gamma_{01}$ dischrg $_{i j}+\mu_{1 j}$ preybio $_{i j}+\mu_{0 j}+r_{i j}$

where $\gamma_{01}$ dischrg $_{i j}$ describes the average effect of discharge at the stream-level on crayfish density. We calculated the ICC score to quantify the amount of variation in crayfish density remaining after adding in both the stream and transect-level predictors.

\section{Results}

The unconditional model estimated that the amount of stream-level variance remaining in the model was $\sigma^{2}=0.0282$ and the residual variance was $\sigma^{2}=0.0094$. Using these variance estimates, we calculated the ICC score which was equal to ICC $=0.7499$. This value suggests that over $74 \%$ of the total variation in crayfish density exists between streams. Therefore, the variance between streams is likely important to understanding transect-level differences. Adding in transect-level predictors (i.e. partial model) reduced site variance to $\sigma^{2}=0.0132$. The ICC score was equal to ICC $=$ 0.5846 , suggesting that $58 \%$ of stream-scale variation in crayfish density remains between streams and that adding in transect-level variables accounted for $16.5 \%$ of the variation in crayfish density (ICC(unconditional) - ICC(partial)).

Finally, results of the fully fit hierarchical model indicated that amount of stream-level variation remaining in the model was $\sigma^{2}=0.004$ (residual variance remained unchanged, $\sigma^{2}=0.0094$ ). At the larger, stream scale, neither algal biomass, prey diversity, or prey biomass were significant predictors of exotic signal crayfish density (Table 1, Fig. 2). Stream discharge was a significant predictor of exotic signal crayfish density at the larger, stream scale ( $\beta=-0.066,95 \% \mathrm{CI}=0.038$; Table 1, Fig. 2). In particular, stream discharge was negatively associated with signal crayfish density, such that as stream discharge increased, signal crayfish density decreased (Fig. 3a. At the smaller, transect-level scale, prey 
Table 1 Results of the fully fit hierarchical linear model

\begin{tabular}{lrl}
\hline Predictor variables & Estimate & $\begin{array}{l}\text { 95\% confidence } \\
\text { interval }\end{array}$ \\
\hline Intercept & 0.2757 & 0.3852 \\
Discharge (stream) & 0.0002 & 0.0138 \\
Preydiversity (stream) & -0.0217 & 0.0742 \\
Preybiomass (stream) & 0.0680 & 0.0551 \\
Algae (stream) & 0.0965 & 0.2695 \\
Discharge (transect) & -0.0658 & 0.0376 \\
Preydiversity (transect) & 0.0981 & 0.1641 \\
Preybiomass (transect) & 0.0273 & 0.0917 \\
Algae (transect) & 0.1256 & 0.3330 \\
\hline
\end{tabular}

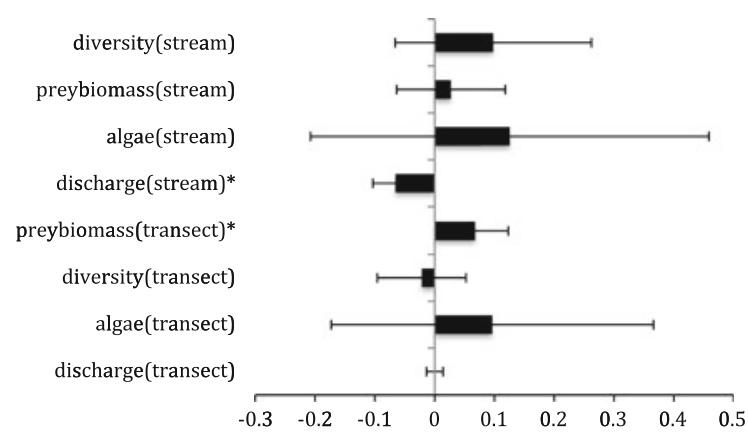

Fig. 2 Scale-explicit predictors of exotic signal crayfish density. Bars represent point estimates of the parameter values. Solid lines represent $95 \%$ confidence intervals for estimated effects of variables at two levels of the model. "Stream" refers to larger, stream scale $\left(\sim 400 \mathrm{~m}^{2}\right)$ parameters and "transect" refers to smaller, transect scale parameters $\left(1 \mathrm{~m}^{2}\right)$. “*” Indicates which variables were significant in the model biomass was the only significant predictor of exotic signal crayfish density $(\beta=0.068,95 \% \mathrm{CI}=0.055$; Fig. 2). In particular, prey biomass was positively associated with signal crayfish density such that as prey biomass increased, signal crayfish density increased (Fig. 3b). Using the variance estimates in the fully fit model, the ICC score was equal to ICC $=0.3200$. Therefore, adding in the stream-level predictors accounted for an additional $26 \%$ of the variation in crayfish density (ICC(partial) - ICC(full)).

\section{Discussion}

Results of the stream survey indicated that annual stream discharge was the key factor influencing the abundance of signal crayfish at a larger stream scale. However, prey biomass better predicted the local abundance of signal crayfish at the smaller, transect scale. These results support the general notion that has emerged from studies on the relationship between native-exotic species richness at a single trophiclevel, which suggest that there is a shift from biotic to abiotic drivers of invasion success as you increase spatial scale. However, contrary to the work on native-exotic species richness, our results suggest that for invasions of an omnivorous crayfish predator, prey biomass as opposed to prey diversity is more important for predator-prey interactions and invasion success at small spatial scales. Below we discuss: (1) how and why abiotic processes, such as annual
Fig. 3 a Plot of the predicted relationship between discharge at the stream-scale and crayfish density, with $\pm 95 \%$ confidence intervals around the regression line. b Plot of the predicted relationship between prey biomass at the transect-scale and crayfish density with $\pm 95 \%$ confidence intervals around the regression line
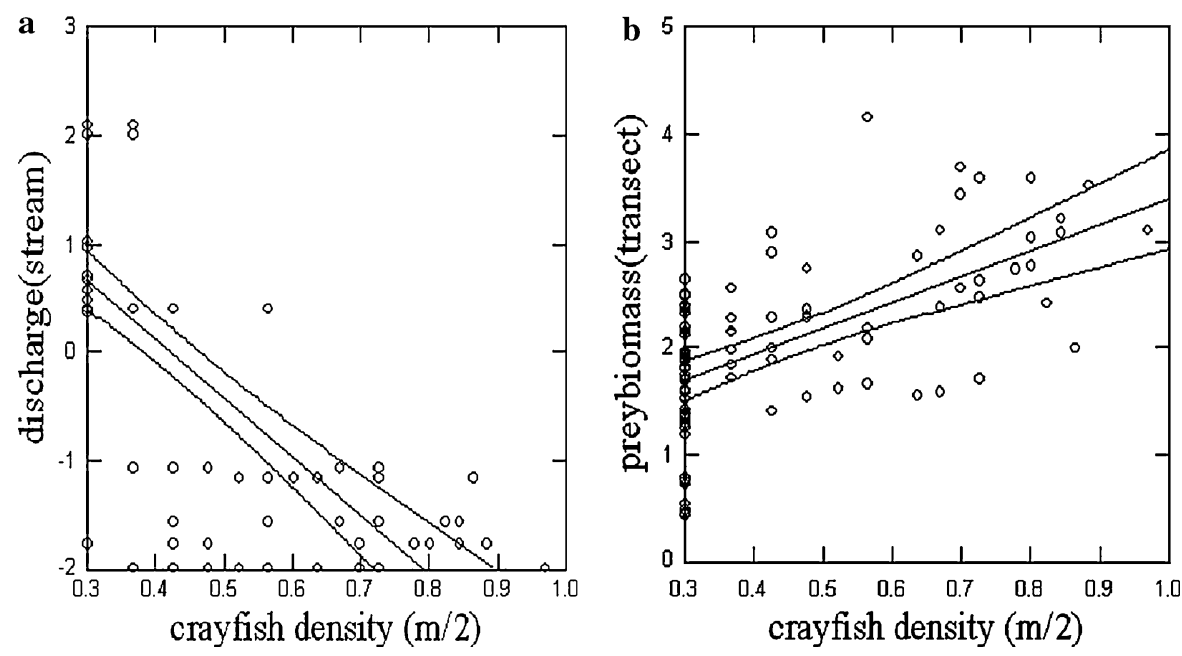
stream discharge, may limit invader abundance across aquatic ecosystems at larger spatial scales, (2) why prey biomass as opposed to prey diversity may be more important for predator invasions at small spatial scales and why neither factor was important at larger scales and (3) how the importance of these factors may depend on an interaction between community characteristics and traits of the invader.

At the larger, stream scale, our results support the emerging generality that at broad spatial scales, invasion success of exotic species is more strongly influenced by abiotic (here, stream discharge) than biotic factors (i.e. prey biomass and diversity) (Fridley et al. 2007). This has been found to be particularly true for aquatic ecosystems, where abiotic forces such as the natural hydrologic regime have been consistently shown to strongly influence invasion success of introduced aquatic species (Moyle and Light 1996b; Marchetti et al. 2004a; Leprieur et al. 2006; Maret et al. 2006; Propst et al. 2008). In particular, the intensity and frequency of high-flow events or spates often limit invasion success and invader abundance of many fish and crayfish species across streams throughout California (Marchetti et al. 2004a; Moyle and Light 1996b). Many watersheds in California show a strong seasonal pattern of low summertime flow rates, but high flow rates in the winter and spring as a consequence of rainfall and snowmelt. As a consequence, many species endemic to California rivers and streams have life histories and traits that make them well adapted to this high seasonality and variability in stream discharge (Moyle and Herbold 1987). Exotic species not well adapted to these hydrologic conditions either fail to establish or are present at low abundances.

In our study, high seasonality did not always exclude signal crayfish, but strongly limited population abundance. These results concur with similar patterns found for the signal crayfish in a stream within the Lake Tahoe watershed, as well as for another invasive crayfish, Procambarus clarkii, in which prolonged and intense wet-season spates limit and reduced crayfish abundance (Light 2003; Kerby et al. 2005). High discharge events often dislodge substrates (i.e. rocks, submerged $\operatorname{logs}$ ) used by crayfish as refuge, which can either increase the likelihood for predation due to increased exposure or cause crayfish to be physically washed downstream and thus, reduce population abundance in newly colonized habitats. Although both species have been shown to be good dispersers that can quickly re-colonize streams following disturbance (in contrast to native crayfish), high stream flow often hinders the upstream dispersal abilities of crayfish and thus, likely limits invader abundance (Bubb et al. 2006; Cruz and Rebelo 2007).

Abiotic processes, such as stream flow, are often more homogenous at smaller spatial scales where biotic processes are thus thought to be better predictors of invasion success (Fridley et al. 2007). Our results concur with this pattern, indicating that as you decrease spatial scale, a biotic variable, prey biomass, that was not a significant predictor of crayfish abundance at larger scales was now the best predictor of invader abundance. In contrast to studies at a single trophic level, we found that for invasions of exotic crayfish, prey biomass as opposed to prey diversity was a key determinant of invasion success. We suggest that prey diversity may not have been a significant predictor of invasion success at either fine or broad scales because of the omnivorous nature and broad diet of signal crayfish (Nyström 2002). Although generalist predators do often show preferences for particular prey, they also readily exploit alternative prey when a preferred prey becomes rare (Bolnick et al. 2003; McEachern et al. 2006). For example, the invasive ladybird beetle, Coccinella septempunctata, will readily exploit alternative prey in alpha fields, when densities of their preferred aphid prey are low and native ladybirds have already dispersed (Evans 2004). Similar patterns have been found with many other invasive generalist predators, leading to the general notion that a broad generalist diet is a common trait contributing to invasion success (Karatayev et al. 2009; Snyder and Evans 2006; Lodge 1993). As such the amount of prey as opposed to the diversity of prey may be a more important factor limiting the abundance of invasive crayfish predators as small scales. At larger spatial scales, because disturbance associated with high stream discharge in some streams apparently keeps invasive signal crayfish from becoming food limited (i.e. limits crayfish abundance), neither prey biomass nor prey diversity had significant effects on streamto-stream variation in crayfish abundances.

Taken together, the effect of stream discharge and prey biomass on crayfish invasion success likely 
depends on an interaction between characteristics of the recipient community and invader traits. At the smaller, within-stream scale, prey diversity may not be an important factor if an exotic predator is an omnivore, a generalist or has a wide diet breadth. However, it is likely that a minimum level of prey abundance is required for an exotic species to establish a population within a newly invaded environment. Signal crayfish, in particular, have been shown to possess a suite of traits that may allow them to overcome low prey abundance in streams that have otherwise not historically supported native crayfish populations (Pintor et al. 2008, 2009). For example, populations of signal crayfish from streams that contain low prey biomass are more active foragers and more bold to forage under predation risk than populations from streams that contain high prey biomass (Pintor et al. 2008). Thus, higher foraging activity may allow signal crayfish to persist in low productivity streams. Similarly, foraging activity and boldness in signal crayfish has also been shown to be positively associated with dispersal activity (Pintor et al. 2009). High dispersal activity may interact with stream discharge and annual flooding across streams to allow crayfish to recolonize sites after a disturbance event. Although stream discharge and prey biomass can limit invader abundance, the fact that these factors cannot exclude signal crayfish from a site suggests that traits like high foraging and dispersal activity, along with boldness interact with community processes to determine the overall level of invasion success.

Acknowledgments We would like to thank Sharon Lawler, Peter Moyle, David Wise, Mary Ashley, Hugh MacIsaac and two anonymous reviewers for their careful reviews and helpful comments on this manuscript. We also thank Jeremy Brooks for his help with the hierarchical modeling. We would like to thank Spring Rivers Ecological Sciences, Marissa Bauer and Chris Mull for their help with the field surveys, and Josh Viers for assistance with the GIS data used in the model and study site map. Additionally, we would like to thank Spring Rivers Ecological Sciences and Jim and Cheryl Bauer for their help with site access and logistical support. This work was supported by a grant from the National and California Sea Grant Program awarded to A. Sih and Lee Kats.

Open Access This article is distributed under the terms of the Creative Commons Attribution Noncommercial License which permits any noncommercial use, distribution, and reproduction in any medium, provided the original author(s) and source are credited.

\section{References}

Alexander JE, Covich AP (1991) Predator avoidance by the freshwater snail Physella virgata in response to the crayfish procambarus simulans. Oecologia 87:435-442

Bolnick DI, Svanback R, Fordyce JA, Yang LH, Davis JM, Hulsey CD, Forister ML (2003) The ecology of individuals: incidence and implications of individual specialization. Am Nat 161(1):1-28

Bubb DH, Thom TJ, Lucas MC (2006) Movement, dispersal and refuge use of co-occurring introduced and native crayfish. Freshwat Biol 51(7):1359-1368

Byers JE, Noonburg EG (2003) Scale dependent effects of biotic resistance to biological invasion. Ecology 84: $1428-1433$

Cox JG, Lima SL (2006) Naivete and an aquatic-terrestrial dichotomy in the effects of introduced predators. Trends Ecol Evol 21(12):674-680

Cruz MJ, Rebelo R (2007) Colonization of freshwater habitats by an introduced crayfish, Procambarus clarkii, in Southwest Iberian Peninsula. Hydrobiologia 575:191201. doi:10.1007/s10750-006-0376-9

Daly C, Neilson RP, Phillips DL (1994) A statistical-topographic model for mapping climatological precipitation over mountainous terrain. J Appl Meteorol 33(2):140-158

Diez JM, Pulliam HR (2007) Hierarchical analysis of species distributions and abundance across environmental gradients. Ecology 88(12):3144-3152

Diez JM, Rulliam HR (2007) Hierarchical analysis of species distributions and abundance across environmental gradients. Ecology 88(12):3144-3152

Diez JM, Buckley HL, Case BS, Harsch MA, Sciligo AR, Wangen SR, Duncan RP (2009) Interacting effects of management and environmental variability at multiple scales on invasive species distributions. J Appl Ecol 46(6):1210-1218. doi:10.1111/j.1365-2664.2009.01725.x

Doggett M, Daly C, Smith J, Gibson W, Taylor G, Johnson G, Pasteris P (2004) High resolution 1971-2000 mean monthly temperature maps for the western United States. Paper presented at the American meteorological society, Seattle, WA, 13-16 Jan 2004

Donlan CJ, Wilcox C (2008) Diversity, invasive species and extinctions in insular ecosystems. J Appl Ecol 45(4): 1114-1123. doi:10.1111/j.1365-2664.2008.01482.x

Duffy JE (2002) Biodiversity and ecosystem function: the consumer connection. Oikos 99:201-219

Ellis MJ (1999) Species invasions and replacements in a native crayfish community. Dissertation, PhD, The University of Michigan, Ann Arbor

ESRI [Environmental Systems Research Institute] (2006) ArcGIS version 9.2. ESRI, Redlands

Evans EW (2004) Habitat displacement of North American ladybirds by an introduced species. Ecology 85:637-647

Fridley JD, Stachowicz JJ, Naeem S, Sax DF, Seabloom EW, Smith MD, Stohlgren TJ, Tilman D, Von Holle B (2007) The invasion paradox: reconciling patterns and process in species invasions. Ecology 88(1):3-17

Gamradt SC, Kats LB (2002) Effect of introduced crayfish and misquitofish on California newts. Conserv Biol 10(4): 1155-1162 
Hillebrand H, Cardinale BJ (2004) Consumer effects decline with prey diversity. Ecol Lett 7:192-201

Karatayev AY, Burlakova LE, Padilla DK, Mastitsky SE, Olenin S (2009) Invaders are not a random selection of species. Biol Invasions 11(9):2009-2019. doi:10.1007/ s10530-009-9498-0

Kerby JL, Riley SPD, Kats LB, Wilson P (2005) Barriers and flow as limiting factors in the spread of an invasive crayfish (Procambarus clarkii) in southern California streams. Biol Conserv 126:402-409

Latimer AM, Wu S, Gelfand AE, Silander JA (2006) Building statistical models to analyze species distributions. Ecol Appl 16:33-50

Leibold MA (1989) Resource edibility and the effects of predators and productivity on the outcome of trophic interactions. Am Nat 134:922-949

Leprieur F, Hickey MA, Arbuckle CJ, Closs GP, Brosse S, Townsend CR (2006) Hydrological disturbance benefits a native fish at the expense of an exotic fish. J Appl Ecol 43(5):930-939. doi:10.1111/j.1365-2664.2006.01201.x

Levine JM, D'Antonio CM (1999) Elton revisited: a review of evidence linking diversity and invasibility. Oikos 87:15-26

Levine JM, Adler PB, Yelenik SG (2004) A meta-analysis of biotic resistance to exotic plant invasions. Ecol Lett 10:975-989

Light T (2003) Success and failure in a lotic crayfish invasion: the roles of hydrologic variability and habitat alteration. Freshwat Biol 48(10):1886-1897

Light T, Erman DC, Myrick C, Clarke J (1995) Decline of the shasta crayfish (Pacifastacus fortis Faxon) of northeastern California. Conserv Biol 9(6):1567-1577

Lodge DM (1993) Biological invasions: lessons for ecology. Trends Ecol Evol 8:133-137

Lodge DM, Kershner MW, Aloi JE, Covich AP (1994) Effects of omnivorous crayfish (Orconectes rusticus) on a freshwater littoral food web. Ecology 75(5):1265-1281

Lodge DM, Taylor CA, Holdrich DM, Skurdal J (2000) Nonindigenous crayfishes threaten North American freshwater biodiversity: lessons from Europe. Fisheries 25:7-17

Marchetti MP, Light T, Moyle PB, Viers JH (2004a) Fish invasions in California watersheds: testing hypotheses using landscape patterns. Ecol Appl 14(5):1507-1525

Marchetti MP, Moyle PB, Levine R (2004b) Alien fishes in California watersheds: characteristics of successful and failed invaders. Ecol Appl 14(2):587-596. doi:10.1890/ 02-5301

Maret TJ, Snyder JD, Collins JP (2006) Altered drying regime controls distribution of endangered salamanders and introduced predators. Biol Conserv 127(2):129-138. doi: 10.1016/j.biocon.2005.08.003

Mccarthy JM, Hein CL, Olden JD, Vander Zanden MJ (2006) Coupling long-term studies with meta-analysis to investigate impacts of non-native crayfish on zoobenthic communities. Freshwat Biol 51(2):224-235

McEachern MB, Eagles-Smith CA, Efferson CM, Van Vuren DH (2006) Evidence for local specialization in a generalist mammalian herbivore, Neotoma fuscipes. Oikos 113(3):440-448
McMahon SM, Diez JM (2007) Scales of association: hierarchical linear models and the measurement of ecological systems. Ecol Lett 10:437-452

Merlo J, Chaix B, Yang M, Lynch J, Rastam L (2005) A brief conceptual tutorial of multilevel analysis in social epidemiology: linking the statistical concept of clustering to the idea of contextual phenomenon. J Epidemiol Community Health 59:443-449

Moyle PB, Herbold B (eds) (1987) Life history patterns and community structure in stream fishes of western North America: comparisons with eastern North America and Europe. Community and evolutionary ecology of North American stream fishes. University of Oklahoma Press, Norman, Oklahoma

Moyle PB, Light T (1996a) Biological invasions of freshwater: empirical rules and assembly theory. Biol Conserv 78: 149-161

Moyle PB, Light T (1996b) Fish invasions in California: do abiotic factors determine success? Ecology 77(6):16661670

Nystrom P (2005) Non-lethal predator effects on the performance of a native and an exotic crayfish species. Freshwat Biol 50(12): 1938-1949

Nyström P (2002) Ecology. In: Holdich DM (ed) Biology of freshwater crayfish. Blackwell Science, Oxford, pp 192-235

Nyström P, Perez JR (1998) Crayfish predation on the common pond snail (Lymnaea stagnalis): the effect of habitat complexity and snail size on foraging efficiency. Hydrobiologia 368:201-208

Pintor LM, Sih A, Bauer ML (2008) Differences in aggression, activity and boldness between native and introduced populations of an invasive crayfish. Oikos 117(11):16291636

Pintor LM, Sih A, Kerby JL (2009) Behavioral correlations provide a mechanism for explaining high invader densities and increased impacts on native prey. Ecology 90(3): 581-587

Poff NL, Ward JV (1989) Implications of streamflow variability and predictability for lotic community structure: a regional analysis of streamflow patterns. Can J Fish Aquat Sci 46(10):1805-1818

Propst DL, Gido KB, Stefferud JA (2008) Natural flow regimes, nonnative fishes, and native fish persistence in arid-land river systems. Ecol Appl 18(5):1236-1252

Rejmanek M (2003) The rich get richer-responses. Front Ecol Environ 1:122-123

Riegel JA (1959) The systematics and distribution of crayfishes in California. Calif Fish Game 45(1):29-50

Sih A, Bolnick DI, Luttbeg B, Orrock JL, Peacor SD, Pintor LM, Preisser EL, Rehage JS, Vonesh JR (2010) Predatorprey naivete, antipredator behavior, and the ecology of predator invasions. Oikos 119(4):610-621

Snyder WE, Evans EW (2006) Ecological effects of invasive arthropod generalist predators. Annu Rev Ecol Evol Syst 37:95-122

Stohlgren T, Barnett D, Flather C, Fuller P, Peterjohn B, Kartesz J, Master L (2006a) Species richness and patterns of invasion in plants, birds, and fishes in the United States*. Biol Invasions 8(3):427-447 
Stohlgren TJ, Jarnevich C, Chong GW, Evangelista PH (2006b) Scale and plant invasions: a theory of biotic acceptance. Preslia 78:405-426

Taylor CA (2002) Taxonomy and conservation of native crayfish stocks. In: Holdich DM (ed) Biology of freshwater crayfish. Blackwell Science, Oxford, pp 236258
Taylor BW, Irwin RE (2004) Linking economic activities to the distribution of exotic plants. Proc Natl Acad Sci USA 101:17725-17730

Wilson KA, Magnuson JJ, Lodge DM, Hill AM, Kratz TK (2004) A long-term rusty crayfish (Orconectes rusticus) invasion: dispersal patterns and community change in a north temperate lake. Can J Fish Aquat Sci 61:2255-2266 